\title{
The Wheat 55K SNP-Based Exploration of Loci for Spikelet Number Per Spike From a Tetraploid Wheat (Triticum Turgidum L.) Recombinant Inbred Line Population Derived From a Chinese Landrace 'ailanmai' and a Wild Emmer Accession
}

\section{Ziqiang Mo}

Sichuan Agricultural University

Jing Zhu

Sichuan Agricultural University

Jiatai Wei

Sichuan Agricultural University

Jieguang Zhou

Sichuan Agricultural University

Qiang Xu

Sichuan Agricultural University

Huaping Tang

Sichuan Agricultural University

Yang Mu

Sichuan Agricultural University

Qiantao Jiang

Sichuan Agricultural University

Yaxi Liu

Sichuan Agricultural University

Guoyue Chen

Sichuan Agricultural University

Jirui Wang

Sichuan Agricultural University

Pengfei Qi

Sichuan Agricultural University

Zhien Pu

Sichuan Agricultural University

Guangdeng Chen

Sichuan Agricultural University 


\section{Yuming Wei}

Sichuan Agricultural University

\section{Youliang Zheng}

Sichuan Agricultural University

\section{Xiujin Lan}

Sichuan Agricultural University

Jian Ma ( $\square$ jianma@sicau.edu.cn )

Sichuan Agricultural University

\section{Research Article}

Keywords: Tetraploid wheat, 55K SNP array, High-quality genetic map, Spikelet number per spike, QTL detection

Posted Date: December 16th, 2020

DOI: https://doi.org/10.21203/rs.3.rs-126308/v1

License: (c) (i) This work is licensed under a Creative Commons Attribution 4.0 International License. Read Full License 


\section{Abstract}

Background: Increasing wheat yield is an urgent task to solve the global food shortage. Spikelet number per spike (SNS) is a key factor in determining kernel number per spike which has a great effect on wheat grain yield. However, modern wheat breeding narrows genetic diversity among cultivars leading to a detrimental effect on future wheat improvement. It is thus of great significance to explore new genetic resources for SNS to increase wheat yield.

Results: A tetraploid landrace 'Ailanmai' $\times$ wild emmer wheat recombinant inbred line (RIL) population was used to construct a high-density genetic map using the wheat $55 \mathrm{~K}$ single nucleotide polymorphism (SNP) array. The results showed that $94.83 \%$ (6204) of the mapped markers had consistent genetic and physical chromosomal locations. Subsequently, fourteen quantitative trait loci (QTL) for SNS explaining 4.23-27.26\% of the phenotypic variation were identified. QSns.sau-AM-2B.3 and QSns.sau-AM-3B.2 were considered as major and novel QTL and their combination had the largest effect and increased SNS by $17.47 \%$. In the physical intervals of QSns.sau-AM-2B.3 and QSns.sau-AM-3B.2, some development-related genes were predicted to participate in the spikelet growth and affect SNS. Additionally, significant correlations between SNS and other agronomic traits like significant and positive correlation between SNS and thousand kernel weight were detected and analyzed.

Conclusions: Our study demonstrated the feasibility of wheat 55K SNP array in genetic mapping of tetraploid wheat and provided an example of exploring outstanding genetic resources from wheat related species for further utilization in common wheat improvement.

\section{Background}

Wheat (Triticum sp.) is one of the most widely planted crops globally and provides about $20 \%$ of the calories consumed by mankind (http://www.fao.org/faostat). With the development of modern society, breeding high-yield wheat cultivars is considered as a sustainable approach to meet the demands of a growing human population.

As we know, the wheat grain yield is composed of spike number per unit area (SNPA), kernel number per spike (KNS), and kernel weight (KW). Additionally, KNS is jointly determined by spikelet number per spike (SNS) and kernel number per spikelet. SNS depends on the number of lateral spikelets produced before the spike meristem transitions to the terminal spikelet which is a complex quantitative trait greatly affected by genetic and environmental factors [1, 2]. Hence, researching the genetic mechanism of SNS at the QTL level will give us more insight into the role of SNS in yield formation [3-6].

So far, a few genes are reportedly related to spikelet number and morphology in wheat. For example, the WHEAT FRIZZY PANICLE (WFZP) gene encodes a member of the APETALA2/ethylene response transcription factor (AP2/ERF) family, which influences the supernumerary spikelet trait in common wheat [7]. Regulatory expression of the two pivotal flowering genes, Photoperiod-1 (Ppd-1) and FLOWERING LOCUS T (FT), can increase the number of fertile spikelets [8]. The inflorescence growth rate 
and the development of paired spikelets are controlled by the TEOSINTE BRANCHED1 (TB1) expression level [9]. WHEAT ORTHOLOG OF APO1 (WAPO1) is the ortholog of the rice APO1 and affects spikelet number in wheat [1]. Overexpression of TaTFL-2D increases the number of wheat spikelet and floret [10]. The wheat transcription factor gene TaNAC67 participates in the regulation of spike length and spikelet number [11].

Given its important role in yield formation, more loci for SNS should be identified and utilized. However, modern wheat breeding reduces the genetic diversity among cultivars and narrows the genetic basis of common wheat leading to a detrimental effect on future wheat improvement [12-14]. Fortunately, a great quantity of undeveloped genetic resources from wheat related species may effectively meet the challenges of future wheat production [15-17].

As the progenitor of modern cultivated tetraploid and hexaploid wheat, wild emmer wheat ( $T$. turgidum subsp. dicoccoides) is the secondary gene source of common wheat. It possesses rich genetic diversity in resistance to various diseases, important agronomic traits and outstanding environmental adaptabilities, and plays a significant role in wheat breeding $[12,18,19]$. For example, Yr15 derived from wild emmer wheat results in resistance to yellow rust [20]. And the reduced-function allele GNI-A1 increases the number of fertile florets per spikelet [21]. Hence, exploiting the genetic resources of wild emmer wheat is extremely crucial to solve the bottlenecks encountered in current wheat breeding. Wheat landraces are also important basic materials for wheat improvement and breeding [22]. They are precious crop resources preserved under long-term natural selection and human intervention, with strong adaptability to local environmental conditions and corresponding production potential [23, 24], harboring some peculiar gene resources yet to be exploited for wheat improvement.

In the current research, we constructed a high-quality genetic map in a tetraploid wheat population developed from the cross between a Chinese wheat landrace 'Ailanmai' and a wild emmer wheat accession using the wheat 55K SNP array. Further, we identified QTL for SNS based on phenptypes measured from multiple environments and the constructed genetic map. Candidate genes in the intervals of the wild emmer genome [25] harboring major and stably expressed SNS QTL were predicted. The correlations between SNS and other agronomic traits including plant height (PH), anthesis date (AD), productive tiller number (PTN), spike length (SL), spike extension length (SEL), kernel number per spike (KNS), and thousand kernel weight (TKW) were also detected and analyzed. Current results broaden our understanding of the application potential of wheat related species in common wheat improvement.

\section{Materials And Methods}

\section{Plant materials}

A tetraploid wheat population (AM population) containing $121 \mathrm{~F}_{8}$ recombinant inbred lines (RILs, including parents) derived from a Chinese landrace 'Ailanmai' (AL, T. turgidum L. cv. Ailanmai, $2 \mathrm{n}=28$, AABB) and a wild emmer accession (LM001, T. turgidum subsp. dicoccoides) was used in this study. 
They were collected and preserved by Triticeae Research Institute, Sichuan Agricultural University. The spikes of $A L$ and LM001 were shown in Fig. 1.

\section{Trait measurement and data analysis}

Trait measurement was conducted from six field environments for AM RILs: Chongzhou (103 $38 \mathrm{E}, 30^{\circ}$ $32 \varangle N)$ in $2017,2018,2019$, and $2020\left(E_{1}, E_{2}, E_{3}\right.$, and $\left.E_{4}\right)$, Wenjiang $\left(103^{\circ} 51 \rrbracket E, 30^{\circ} 43 \varangle N\right)$ in $2020\left(E_{5}\right)$, and Ya'an $\left(103^{\circ} 0 \otimes \mathrm{E}, 29^{\circ} 58 \otimes \mathrm{N}\right)$ in $2020\left(\mathrm{E}_{6}\right)$.

Field experiments were carried out in a randomized complete block design with two replications and were managed in accord with the conventional practices of wheat production. Each plot for a single line was space-planted $(0.1-\mathrm{m})$ in a single $1.5-\mathrm{m}$ row with a $0.3-\mathrm{m}$ of row spacing [26]. The measuring methods of partial agronomic traits were similar to Liu et al. [27]: SNS was measured by calculating the spikelet number of main-spike; PH was determined by the distance from the soil surface to the tip of main-spike (excluding awns); PTN was represented by the number of productive tiller per plant; SL was counted by the length from the base to the tip of main-spike (excluding awns); KNS was measured as the kernel number of main-spike; TKW was represented by 1000 times of the average kernel weight of main-spike. $A D$ was measured from the sowing date to the date that half of the plants of each line flowered [3]. SEL was measured as the distance from the base of the spike to the petiole of the flag leaf [28]. At least three randomly selected plants with consistent growth status were measured for the above traits and averaged for further analysis. The detailed environments for measuring these agronomic traits were listed in Additional file 1.

The basic analysis of the phenotypic data including Pearson's correlation, frequency distribution, standard error, and Student's $t$-test $(P<0.05)$ was performed using IBM SPSS Statistics 25 (http://en.wikipedia.org/wiki/SPSS). The broad-sense heritability $\left(H^{2}\right)$ and best linear unbiased prediction (BLUP) of agronomic traits from different environments were calculated by SAS version 8.0 (https://www.sas.com).

\section{Genetic map construction}

High-quality genomic DNA was isolated from fresh leaves of AM RILs following the instructions of Plant Genomic DNA Kit (Tiangen Biotech, Beijing China). The DNA of each line was genotyped using the wheat 55K SNP array from CapitalBio Technology (Beijing, China).

The construction processes of genetic map were consistent with the methods of Liu et al. [29].

Specifically, markers from the group of Poly High Resolution in the wheat 55K SNP array were retained for the next analysis. Further, markers showing minor allele frequency $(<0.3)$ among the AM RILs were removed, and markers from the $D$ genome were also deleted. According to their separation patterns in AM RILs, the parameters 'Distortion value' and 'Missing rate' were set as 0.01 and $20 \%$, respectively. The remaining SNP markers were analyzed using the BIN function of IciMapping 4.1

(http://www.isbreeding.net/). Only the marker with 'deleted = 0' from each bin (bin marker) was selected 
to construct genetic maps. The bin markers were sorted with Kosambi mapping function in JoinMap 4.0 (https://www.kyazma.nl/index.php/JoinMap/) and the minimum LOD value was set as 5 . The genetic maps were drawn using MapChart 2.3.2 (http://www.biometris.nl/uk/Software/MapChart/). The syntenic relationships between the genetic and physical maps of bin markers were further carried out by Strawberry Perl 5.24.0.1 (http://perldoc.perl.org/perlintro.html).

\section{QTL analysis}

QTL analysis for SNS was performed using the inclusive composite interval mapping (ICIM) in the Biparental Populations (BIP) module of IciMapping 4.1, and the minimal LOD score was set as 2.5. The QTL-by-Environment interaction was analyzed by the multi-environment trials (MET) pattern of IciMapping 4.1.

QTL were named according to the provision of Genetic Nomenclature (http://wheat.pw.usda.gov/ggpages/wgc/98/Intro.htm). 'Sns' and 'sau' represented 'spikelet number per spike' and 'Sichuan Agricultural University', respectively. Besides, we added the RILs' name 'AM' to QTL's name to distinguish them from others reported previously.

The sequences of SNP markers were blasted against the wild emmer (https://www.dropbox.com/sh/3dm05grokh10nbv/AAC3wv1YmAher8fY0srX3gX9a?dl=0\%22) [25] and common wheat genotype 'Chinese Spring' (CS) genomes (IWGSC RefSeq v1.0; https://urgi.versailles.inra.fr/download/iwgsc/) to get their physical positions. Predicted genes mapped between the flanking markers were gained from the Triticeae Multi-omics Center (http://202.194.139.32/), and their annotation and function were further analyzed using UniProt (http://www.uniprot.org/).

\section{Results}

\section{SNP markers and genetic map}

As suggested by the Affymetrix Company, the probes from the group of Poly High Resolution with high probability should be reserved. Thus, we retained markers from the A and $B$ genome with minor allele frequency (>0.3) among the SNP markers from the group of Ploy High Resolution. Finally, 7901 SNP markers were classified into 1192 bins, and one marker from each bin was screened to construct the genetic map. The linkage analysis results revealed that 1150 bin markers were mapped on the 15 genetic maps. Subsequently, 6542 co-segregated SNP markers were integrated into the genetic map based on the bin information.

The 1150 bin markers were mapped on 15 linkage groups spanning $2411.78 \mathrm{cM}$ for the 14 chromosomes in tetraploid wheat, and one linkage group was constructed each for all chromosomes except chromosome 3B for which two were obtained (Table 1; Additional file 2). The average distance of bin markers ranged from $1.09 \mathrm{cM}(4 \mathrm{~B})$ to $3.64 \mathrm{cM}$ (3B2), with an average density of one bin marker per 2.10 cM (Table 1; Additional file 2). The lengths of genetic maps ranged from $49.69 \mathrm{cM}$ (3B1) to $225.06 \mathrm{cM}$ 
(5A) (Table 1; Additional file 2). Among the 1150 bins, 450 bins contained only one marker, the largest bin included 561 markers on chromosome 2A (Additional file 3).

The mapped markers (including bin markers and co-segregated markers) ranged from 37 on chromosome 3B1 to 944 on chromosome $2 A$. What's more, $56 \%$ of the mapped markers were distributed on A genomes, and $44 \%$ of those were mapped on B genomes (Table 1; Additional file 3 ).

\section{Comparison of genetic and physical maps}

Based on the sequences of SNP markers, the 6542 mapped markers were blasted against wild emmer and CS reference genomes to get their physical positions, respectively (Additional file 3). Subsequently, we compared the genetic and physical chromosomal locations of 1150 bin markers in the wild emmer genome: 35 (3.04\%) bin markers showed inconsistent chromosomal locations, 49 (4.26\%) bin markers were mapped on unknown chromosomes, and the rest of bin markers were well matched (Fig. 2; Fig. 3; Additional file 3).

Similarly, we also compared the genetic and physical chromosomal locations of all the 6542 mapped markers in the wild emmer genome. The results showed that $125(1.91 \%)$ markers were mapped on the unknown chromosomes, and 213 (3.26\%) markers were mapped on inconsistent chromosomal locations (Additional file 3). The genetic and physical location of each remaining marker was identical and had roughly the same SNP order (Additional file 3; Additional file 4).

Among the 6542 mapped markers, the physical chromosomal locations of 295 (4.51\%) markers were inconsistent on wild emmer and CS reference genomes, and those of the remaining markers (6247, 95.49\%) showed good consistencies.

\section{Phenotypic variation}

The SNS of AL and LM001 in six environments ranged from 25.00 to 27.00 and from 23.33 to 26.00, respectively, and that of AM RILs from 15.33 to 34.00 (Table 2). The broad-sense heritability $\left(H^{2}\right)$ of SNS was 0.82 (Table 2), indicating that the SNS trait of the AM population was mainly controlled by genetic factors than environmental factors. Significant correlation coefficients ranging from 0.500 to 0.761 of SNS between six environments were detected (Table 3). In addition, the frequency distribution of SNS indicated that SNS was polygenic inheritance in multiple environments (Additional file 5).

\section{Pearson's correlations between SNS and other agronomic traits}

Pearson's correlations were analyzed between SNS and seven other agronomic traits based on the BLUP values. SNS was significantly and positively correlated with PH, AD, SL, SEL, KNS, and TKW (Table 4). No significant correlation was observed between SNS and PTN (Table 4).

\section{Analysis of SNS QTL}


A total of fourteen QTL were identified in the AM RIL population. They were distributed on chromosomes $1 \mathrm{~A}(1 \mathrm{QTL}), 3 \mathrm{~A}(1), 5 \mathrm{~A}(2), 6 \mathrm{~A}(1), 2 \mathrm{~B}(3), 3 \mathrm{~B}(2), 4 \mathrm{~B}(1), 5 B(2)$ and 6B (1), with LOD scores from 2.53 to 13.28 and explained $4.23-27.26 \%$ of the phenotypic variation (Table 5). The positive alleles of eight QTL were from AL and those of the other six were contributed by LM001. Four QTL were detected in at least two environments and the other ten only in a single environment (Table 5).

QSns.sau-AM-5A.2 was identified in two environments and located in a $19.10 \mathrm{cM}$ region between $A X$ 108790581 and $A X-111596791$. It accounted for $6.69-14.34 \%$ of the phenotypic variation (Table 5). AM RILs were divided into two categories based on the genotype of this QTL's flanking markers. The SNS of the lines with the positive allele was significantly higher than that with the negative allele from QSns.sauAM-5A.2 (Fig. 4a).

QSns.sau-AM-2B.3 was stably identified in all environments and explained 9.64-27.26\% of the phenotypic variation. It was located in a $1.79 \mathrm{cM}$ region between $A X-111626925$ and $A X-111588559$ (Table 5). The additive effect of $Q S n s . s a u-A M-2 B .3$ was negative, indicating that the increasing-SNS allele was contributed by LM001 (Table 5; Fig. 4b).

QSns.sau-AM-3B.1 and QSns.sau-AM-3B.2 were detected in two and four environments, respectively. They explained up to $18.06 \%$ and $13.74 \%$ of the phenotypic variation (Table 5). The positive alleles of QSns.sau-AM-3B.1 and QSns.sau-AM-3B.2 were both from AL. As expected, lines carrying the positive allele of either QSns.sau-AM-3B.1 or QSns.sau-AM-3B.2 had higher SNS than those with the negative allele (Fig. 4c, d).

Forty-two QTL were identified in the QTL-by-Environment interaction analysis (Additional file 6). Nine of them, including QSns.sau-AM-5A.2, QSns.sau-AM-2B.3, QSns.sau-AM-3B.1, and QSns.sau-AM-3B.2, were the same as detected in individual environment analysis. These results indicated that these nine QTL were stably expressed for SNS.

\section{Effects of two major QTL on increasing SNS}

In this study, two major and stably expressed QTL (i.e. QSns.sau-AM-2B.3 and QSns.sau-AM-3B.2) were identified for SNS in more than three environments. Their effects on increasing SNS were further revealed based on the genotype of flanking markers by Student's $t$-test (Fig. 5).

Compared with the lines carried the negative alleles from two major QTL, the lines with the positive allele of QSns.sau-AM-2B.3 significantly increased SNS by 8.23\%; those with the positive allele of QSns.sau$A M-3 B .2$ significantly increased SNS by $6.52 \%$; the combined effects of two major QTL significantly increased SNS by $17.47 \%$ (Fig. 5). The results showed that QSns.sau-AM-2B.3 had the largest effect on increasing SNS among the two major QTL, and there were no significant differences between the effects of QSns.sau-AM-2B.3 and QSns.sau-AM-3B.2 on increasing SNS (Fig. 5). Compared with the lines which just carried the positive allele from QSns.sau-AM-2B.3 or QSns.sau-AM-3B.2, the combined effects of QSns.sau-AM-2B.3 and QSns.sau-AM-3B.2 increased SNS by $8.53 \%$ and $10.28 \%$, respectively (Fig. 5). 


\section{Effects of two major QTL on other agronomic traits}

To analyze the effects of the two major QTL (i.e. QSns.sau-AM-2B.3 and QSns.sau-AM-3B.2) on other agronomic traits, AM RILs were divided into two categories based on the genotype of flanking markers of two major QTL: lines with the positive alleles of two major QTL and lines carried the negative alleles from them. The analysis results between the two categories showed that the combined effects QSns.sau-AM2B.3 and QSns.sau-AM-3B.2 significantly influenced the SL, SEL, and KNS, but not significantly affected $\mathrm{PH}, \mathrm{AD}, \mathrm{PTN}$, and TKW (Fig. 6).

\section{Discussion}

\section{The feasibility of wheat 55K SNP array in QTL mapping of tetraploid wheat}

The wheat 55K SNP array has been widely used for genotyping and QTL identification mostly in hexaploid common wheat [30-32]. In the current study, the wheat 55K SNP array was employed for genotyping a tetraploid wheat RIL population and a high-quality genetic linkage map was constructed. Further, two major QTL for SNS were detected. These results confirmed the feasibility of wheat 55K SNP array in the genetic mapping of tetraploid wheat.

\section{Exploration of loci for SNS from tetraploid wheat species}

Previous studies discussed the SNS in tetraploid wheat at the QTL level. Peng et al. [33] identified QTL for SNS on chromosomes $1 \mathrm{~B}, 2 \mathrm{~A}, 5 \mathrm{~A}$, and $6 \mathrm{~B}$ in an $\mathrm{F}_{2}$ wild emmer $\times$ durum wheat population with a total of $49.3 \%$ phenotypic variation explained. Four QTL for SNS were detected on 1B, 3B, 7A, and 7B chromosomes in a tetraploid wheat RIL population developed from the cross between durum wheat and cultivated emmer wheat [34]. QSpn.fCu-2A was detected from the durum wheat Langdon $\times$ Langdon-wild emmer wheat substitution lines population and explained $19.4 \%$ of the phenotypic variation [35]. QSpn.fCu-1B and QSpn.fCu-5A were identified with 5.1 and 11.4 of LOD scores, respectively, in a durum wheat $\times$ cultivated emmer population [36]. These previous reports enhanced our understanding of the SNS in tetraploid wheat.

In the current research, the positive alleles of major and stably expressed QTL QSns.sau-AM-2B.3 and QSns.sau-AM-3B.2 were contributed by wild emmer wheat and Chinese landrace 'Ailanmai', respectively. Compared with lines possessed the negative alleles from two major QTL, the combined effects of two major QTL significantly increased SNS by $17.47 \%$ (Fig. 5). We considered that QSns.sau-AM-2B.3 and QSns.sau-AM-3B.2 identified in tetraploid wheat species had higher application potential for wheat yield improvement.

\section{Comparison of the major QTL identified for SNS with previous studies}

No significant differences for SNS were detected between the parents AL and LM001 in multiple environments (Table 2). However, the phenotypic data of SNS in six environments showed approximately 
normal distribution (Additional file 5), and we further identified two major and stably expressed QTL for SNS. The possible explanation for this phenomenon was that transgressive inheritance occurred in progenies and resulted in the bidirectional segregation of SNS. It was deduced that several genes controlling SNS might be inhibited each other in a given parental genotype resulting in the absence of the corresponding phenotype in the parents. However, the single locus produced by genetic recombination between parental genotypes displayed an obvious phenotype in progenies without interference by other loci that control the same traits. Hence, we could identify major SNS loci in the AM RIL population. This was not uncommon in the past studies of QTL identification based on RIL populations [27, 37].

To further identify whether QSns.sau-AM-2B.3 and QSns.sau-AM-3B.2 were novel QTL, we physically located previous SNS QTL on chromosome $2 \mathrm{~B}$ and $3 \mathrm{~B}$ in wild emmer and CS reference genomes (Additional file 7). QSns.sau-AM-2B.3 was physically located on chromosome arm 2BL at 714.47-717.09 Mbp (Fig. 7a). Some QTL for SNS were detected on chromosome arm 2BS in previous studies, but none was reported on 2BL (Additional file 7). For example, Qspn-2007 was identified on chromosome 2B with the closest marker Xgwm429 (73.62 Mbp) [38]. QFsn.sdau-2B-1 was located on chromosome arm 2BS and explained up to $28.43 \%$ of the phenotypic variation [39]. Xie et al. [40] detected three QTL for SNS on chromosome arm 2BS in an $F_{5}$ RIL population. And some genes that affected SNS were detected on chromosome arm 2BS, such as Ppd-B1 [41] and WFZP-2B [7].

QSns.sau-AM-3B.2 was physically located on chromosome arm 3BS at 62.41-65.16 Mbp (Fig. 7b). In previous studies, Azadi et al. [42] detected four QTL for SNS on chromosome arm 3BL. QSpn.fcu-3B was located at 74.28-120.61 Mbp with flanking markers IWA3716 and IWA6201 [34]. Cui et al. [43] identified two QTL named QSpn.WJ.3B.1 and QSpn.WY.3B.1 all closely linked to the locus Xgwm566 (77.72 Mbp).

Comparison of physical positions of QSns.sau-AM-2B.3 and QSns.sau-AM-3B.2 with those reported previously showed that they were not overlapped with known SNS QTL, further indicating that they were probably novel QTL controlling SNS in tetraploid wheat.

\section{Predicted genes in the physical intervals of major QTL}

QSns.sau-AM-2B.3 was physically located in 709.43-712.30 Mbp and 714.47-717.09 Mbp of wild emmer and CS reference genomes, respectively (Fig. 7a). In the corresponding intervals, there were 32 and 27 predicted genes, respectively (Additional files 8 ). Additionally, 18 functional orthologs were found among the predicted genes of QSns.sau-AM-2B.3 (Additional files 8). QSns.sau-AM-3B.2 was detected in 70.9273.35 Mbp and 62.41-65.16 Mbp of wild emmer and CS reference genomes, respectively, and there were 24 functional orthologs (Fig. 7b; Additional files 9).

Of these orthologs, TRIDC2BG075100 and TRIDC3BG013290 were members of the F-box protein family. Previous studies showed that the F-box family protein played vital roles in the control of flowering time, floral organ development, and cell proliferation [44-46]. TRIDC2BG075120 encoded an IQ-domain 32 protein that cooperated with calmodulin to regulate the basic defense response and the growth of plants [47]. TRIDC2BG075260 encoded a serine hydroxymethyltransferase (SHMT) which was a key enzyme in 
plant photorespiration. Lack of SHMT could cause severe growth delay and weaken resistance to abiotic stress [48]. TRIDC3BG013250 was a member of Receptor-like protein kinases (RLKs). And RLKs were known to be involved in signal transduction, plant growth and development [49]. The above-mentioned genes all played an important role in plant growth and development, which might participate in the formation of wheat spikelet and affect SNS. In general, these results provided the foundation for our following work in fine mapping and gene cloning of major QTL.

\section{Significantcorrelations between SNS and other agronomic traits}

A significant and positive correlation was observed between SNS and SL (Table 4). We could understand it as the increase in SL required a longer spike development stage in combination with optimal temperature and light promoting the germination of more spikelets in wheat [50,51]. SNS was significantly and positively correlated with PH in our results (Table 4), which was supported by the conclusions from Ajmal et al. [52] and Wu et al. [53]. We speculated that SL was part of PH, and the higher plant had a long spike with more spikelets [54]. A significant and positive relationship was detected between SNS and AD (Table 4), confirming the results by Ma et al. [3]. Previous studies suggested that the wheat plants with later flowering dates might produce longer spikes with more spikelets $[8,51,55]$. These results indicated that AD played an important role in the formation of spikelet. On the whole, floret fertility determined the KNS in wheat, and thus more spikelets would produce more fertile florets accompanied with an increase of KNS $[2,21]$. This was likely the reason why SNS was significantly and positively correlated with KNS (Table 4).

It was generally believed that a negative correlation should be observed between SNS and TKW $[3,56]$ due to a source limitation during kernel filling or the existence of more kernels with lower KW in the distal positions of the spike [57]. Previous studies also suggested that SNS was negatively correlated with SEL because of the competition for assimilating products between SNS and SEL [58-60]. The above conclusions were inconsistent with our study that SNS was significantly and positively correlated with TKW and SEL (Table 4). Our further results also revealed there were significant differences in the SEL between two types (lines with or without the positive alleles from major QTL) (Fig. 6e). It probably indicated that the loci controlling SNS played an individual role without interaction with SEL. According to the previous studies, SEL had a special function in photosynthesis and the storage of nutrients and water, hence, a longer SEL would be more conducive to ventilation and transporting more nutrients and water to kernels [61, 62], finally likely increasing the KW. Thus, SNS was significantly and positively correlated with SEL and TKW in the current study. These conclusions were helpful for us to comprehensively consider the complex relationship in agronomic traits and might provide new insights into wheat yield improvement.

\section{Conclusions}

In the current study, the wheat 55K SNP array was successfully applied to construct a high-quality genetic map and explore two major and novel QTL (i.e. QSns.sau-AM-2B.3 and QSns.sau-AM-3B.2) for SNS in a tetraploid wheat RIL population. The effects of major QTL on increasing SNS were further revealed. We 
also discussed the significant correlations between SNS and other agronomic traits and predicted some development-related genes in the physical intervals of major QTL which might affect SNS. Our findings demonstrated the feasibility of wheat 55K SNP array in genetic mapping of tetraploid wheat and showed the application potentiality of wheat related species in common wheat improvement.

\section{Abbreviations}

QTL: Quantitative trait loci; SNS: Spikelet number per spike; RILs: Recombinant inbred lines; SNP: single nucleotide polymorphism; PH: Plant height; AD: Anthesis date; PTN: Productive tiller number; SL: Spike length; SEL: Spike extension length; KNS: Kernel number per spike; TKW: Thousand kernel weight; CS: Chinese Spring; BLUP: Best linear unbiased prediction; LOD: Logarithm of odds; PVE: Phenotypic variation values; $H^{2}$ : Broad-sense heritability

\section{Declarations}

\section{Acknowledgments}

Not applicable

\section{Author contributions}

ZQM and JZ conducted the study and drafted this manuscript. JTW and JGZ participated in phenotype measurement and data analysis. QX and HPT helped with field work and data analysis. YM, QTJ, and YXL participated in data collection and analysis. GYC, JRW, PFQ, ZEP, and GDC did QTL analysis and manuscript revision. YMW and YLZ discussed the results and revised the manuscript. XJL guided the study and revised the manuscript. JM designed the experiments, guided the entire study, participated in data analysis, wrote and extensively revised this manuscript. All authors participated in the research and approved the final manuscript.

\section{Funding}

This work is supported by the National Natural Science Foundation of China (31971937 and 31970243), the Key Research and Development Program of Sichuan Province (2018NZDZX0002), the Applied Basic Research Programs of Science and Technology Department of Sichuan Province (2020YJ0140 and 21YYJC1556), the International Science and Technology Cooperation and Exchanges Program of Science and Technology Department of Sichuan Province (21GJHZ0157), and the Key Projects of Scientific and Technological Activities for Overseas Students of Sichuan Province. The funders did not participate in the study design, data analysis, or preparation of the manuscript.

\section{Availability of data and materials}

All data generated or analyzed during this study are included in this published article and its supplementary information files. 


\section{Ethics approval and consent to participate}

All experiments and data analyses were conducted in Sichuan. All authors contributed to the study and approved the final version for submission.

\section{Consent for publication}

Not applicable.

\section{Competing interests}

The authors declare that they have no competing interests.

\section{Author details}

${ }^{1}$ State Key Laboratory of Crop Gene Exploration and Utilization in Southwest China, Triticeae Research Institute, Sichuan Agricultural University, Chengdu, 611130, China

${ }^{2}$ College of Agronomy, Sichuan Agricultural University, Chengdu, 611130, China

${ }^{3}$ College of Resources, Sichuan Agricultural University, Chengdu, 611130, China

\section{References}

1. Kuzay S, Xu YF, Zhang JL, Katz A, Pearce S, Su ZQ, et al. Identification of a candidate gene for a QTL for spikelet number per spike on wheat chromosome arm 7AL by high-resolution genetic mapping. Theor Appl Genet. 2019;132 (9):2689-2705.

2. Gao XQ, Wang N, Wang XL, Zhang XS. Architecture of wheat inflorescence: insights from rice. Trends Plant Sci. 2019;24:802-809.

3. Ma J, Ding PY, Liu JJ, Li T, Zou YY, Habib A, et al. Identification and validation of a major and stably expressed QTL for spikelet number per spike in bread wheat. Theor Appl Genet. 2019;132(11):31553167.

4. Yao HN, Xie Q, Xue SL, Luo J, Lu JK, Kong ZX, et al. HL2 on chromosome 7D of wheat (Triticum aestivum L.) regulates both head length and spikelet number. Theor Appl Genet 2019;132(6):17891797.

5. Wang R, Liu YX, Isham K, Zhao WD, Wheeler J, Klassen N, et al. QTL identification and KASP marker development for productive tiller and fertile spikelet numbers in two high-yielding hard white spring wheat cultivars. Mol Breed. 2018;38(11):135.

6. Chen ZY, Cheng XJ, Chai LL, Wang ZH, Du DJ, Wang ZH, et al. Pleiotropic QTL influencing spikelet number and heading date in common wheat (Triticum aestivum L.). Theor Appl Genet. 2020;133(6):1825-1838. 
7. Dobrovolskaya O, Pont C, Sibout R, Martinek P, Badaeva E, Murat F, et al. FRIZZY PANICLE drives supernumerary spikelets in bread wheat. Plant Physiol. 2015;167:189-199.

8. Boden SA, Cavanagh C, Cullis BR, Ramm K, Greenwood J, Jean Finnegan E, et al. Ppd-1 is a key regulator of inflorescence architecture and paired spikelet development in wheat. Nat Plants. 2015;1(2):14016.

9. Dixon LE, Greenwood JR, Bencivenga S, Zhang P, Cockram J, Mellers G, et al. TEOSINTE BRANCHED1 regulates inflorescence architecture and development in bread wheat (Triticum aestivum). Plant Cell. 2018;30(3):563-581.

10. Wang YG, Yu HP, Tian CH, Sajjad M, Gao CX, Tong YP, et al. Transcriptome association identifies regulators of wheat spike architecture. Plant Physiol. 2017;175(2):746-757.

11. Zhang H, Li Y, Miao L, Wang J, Li C, Yang D, et al. Transcription factor gene TaNAC67involved in regulation spike length and spikelet number per spike in common wheat. Acta Agron Sin. 2019;45(11):1615-1627 (in Chinese with English abstract).

12. Tanksley SD, McCouch SR. Seed banks and molecular maps: unlocking genetic potential from the wild. Science. 1997;277(5329):1063-1066.

13. Cavanagh CR, Chao SM, Wang SC, Huang BE, Stephen S, Kiani S, et al. Genome-wide comparative diversity uncovers multiple targets of selection for improvement in hexaploid wheat landraces and cultivars. Proc Natl Acad Sci U S A. 2013;110(20):8057-8062.

14. Sthapit SR, Marlowe K, Covarrubias DC, Ruff TM, Eagle JD, McGinty EM, et al. Genetic diversity in historical and modern wheat varieties of the U.S. Pacific Northwest. Crop Sci. 2020;60:3175-3190.

15. Reynolds M, Bonnett D, Chapman SC, Furbank RT, Manes Y, Mather DE, et al. Raising yield potential of wheat. I. Overview of a consortium approach and breeding strategies. J Exp Bot. 2011;62(2):439452.

16. Longin CFH, Reif JC. Redesigning the exploitation of wheat genetic resources. Trends Plant Sci. 2014;19(10):631-636.

17. Martínez-Moreno F, Solís I, Noguero D, Blanco A, Özberk I, Nsarellah N, et al. Durum wheat in the Mediterranean Rim: historical evolution and genetic resources. Genet Resour Crop Evol. 2020;67:1415-1436.

18. Xie WL, Nevo E. Wild emmer: genetic resources, gene mapping and potential for wheat improvement. Euphytica. 2008;164(3):603-614.

19. Yu JS, Zhao YH, Ding MQ, Yu ZT, Jiang YR, Ma WJ, et al. Wild emmer chromosome arm substitution lines: Useful resources for wheat genetic study and breeding. Crop Sci. 2020;60:1761-1769.

20. Klymiuk V, Yaniv E, Huang L, Raats D, Fatiukha A, Chen S, et al. Cloning of the wheat Yr15 resistance gene sheds light on the plant tandem kinase-pseudokinase family. Nat Commun. 2018;9(1):3735.

21. Sakuma S, Golan G, Guo Z, Ogawa T, Tagiri A, Sugimoto K, et al. Unleashing floret fertility in wheat through the mutation of a homeobox gene. Proc Natl Acad Sci U S A. 2019;116:5182-5187. 
22. Lin Y, Chen GD, Hu HY, Yang XL, Zhang ZL, Jiang XJ, et al. Phenotypic and genetic variation in phosphorus-deficiency-tolerance traits in Chinese wheat landraces. BMC Plant Biol. 2020;20(1):330.

23. Crossa J, Jarquin D, Franco J, Perezrodriguez P, Burgueno J, Saintpierre C, et al. Genomic prediction of gene bank wheat landraces. G3-Genes Genomes Genet. 2016;6(7):1819-1834.

24. Lopes MS, Ibrahim EB, Baenziger PS, Sukhwinder S, Conxita R, Kursad O, et al. Exploiting genetic diversity from landraces in wheat breeding for adaptation to climate change. J Exp Bot. 2015;66(12):3477-3486.

25. Avni R, Nave M, Barad O, Baruch K, Twardziok S, Gundlach H, et al. Wild emmer genome architecture and diversity elucidate wheat evolution and domestication. Science. 2017;357(6346):93-97.

26. Ma J, Qin NN, Cai B, Chen GY, Ding PY, Zhang H, et al. Identification and validation of a novel major QTL for all-stage stripe rust resistance on 1BL in the winter wheat line 20828. Theor Appl Genet. 2019;132(5):1363-1373.

27. Liu H, Ma J, Tu Y, Zhu J, Ding PY, Liu JJ, et al. Several stably expressed QTL for spike density of common wheat (Triticum aestivum) in multiple environments. Plant Breed. 2020;139:284-294.

28. Tao Y, Yi X, Lin Y, Wang ZQ, Wu FK, Jiang XJ, et al. Quantitative trait locus mapping for panicle exsertion length in common wheat using two related recombinant inbred line populations. Euphytica. 2019;215(6):104.

29. Liu JJ, Luo W, Qin NN, Ding PY, Zhang H, Yang CC, et al. A 55 K SNP array-based genetic map and its utilization in QTL mapping for productive tiller number in common wheat. Theor Appl Genet. 2018;131(11):2439-2450.

30. Ren TH, Hu YS, Tang YZ, Li CS, Yan BJ, Ren ZL, et al. Utilization of a wheat55K SNP array for mapping of major QTL for temporal expression of the tiller number. Front Plant Sci. 2018;9:333.

31. Ma J, Tu Y, Zhu J, Luo W, Liu H, Li C, et al. Flag leaf size and posture of bread wheat: genetic dissection, QTL validation and their relationships with yield-related traits. Theor Appl Genet. 2020;133(1):297-315.

32. Liu JJ, Tang HP, Qu XR, Liu H, Li C, Tu Y, et al. A novel, major, and validated QTL for the effective tiller number located on chromosome arm 1BL in bread wheat. Plant Mol Biol. 2020;104(1):173-185.

33. Peng JH, Korol A, Fahima T, Roder M, Li Y, Nevo E. QTLs for agronomic traits in tetraploid wild emmer wheat, Triticum dicoccoides. J Sichuan Agric Univ. 2001;19:317-334 (in Chinese with English abstract).

34. Faris JD, Zhang QJ, Chao SM, Zhang ZC, Xu SS. Analysis of agronomic and domestication traits in a durum $\times$ cultivated emmer wheat population using a high-density single nucleotide polymorphismbased linkage map. Theor Appl Genet. 2014;127:2333-2348.

35. Faris JD, Zhang ZC, Garvin DF, Xu SS. Molecular and comparative mapping of genes governing spike compactness from wild emmer wheat. Mol Genet Genomics. 2014;289(4):641-651.

36. Sharma JS, Running KLD, Xu SS, Zhang QJ, Peters Haugrud AR, Sharma S, et al. Genetic analysis of threshability and other spike traits in the evolution of cultivated emmer to fully domesticated durum wheat. Mol Genet Genomics. 2019;294(3):757-771. 
37. Shang QQ, Zhang DG, Li R, Wang KX, Cheng ZM, Zhou ZQ, et al. Mapping quantitative trait loci associated with stem-related traits in maize (Zea mays L.). Plant Mol Biol. 2020;104:583-595.

38. Manickavelu A, Kawaura K, Imamura H, Mori M, Ogihara Y. Molecular mapping of quantitative trait loci for domestication traits and $\beta$-glucan content in a wheat recombinant inbred line population. Euphytica. 2011;177(2):179-190.

39. Deng ZY, Cui Y, Han QD, Fang WQ, Li JF, Tian JC. Discovery of consistent QTLs of wheat spike-related traits under nitrogen treatment at different development stages. Front Plant Sci. 2017;8:2120.

40. Xie Q, Sean M, Sparkes DL. Spelt as a genetic resource for yield component improvement in bread wheat. Crop Sci. 2015;55(6):2753-2765.

41. Mohler V, Lukman R, Ortiz-Islas S, William M, Worland AJ, van Beem J, et al. Genetic and physical mapping of photoperiod insensitive gene Ppd-B1 in common wheat. Euphytica. 2004;138(1):33-40.

42. Azadi A, Mardi M, Hervan EM, Mohammadi SA, Moradi F, Tabatabaee MT, et al. QTL mapping of yield and yield components under normal and salt-stress conditions in bread wheat (Triticum aestivum L.). Plant Mol Biol Rep. 2015;33(1):102-120.

43. Cui F, Ding AM, Li J, Zhao CH, Wang L, Wang XQ, et al. QTL detection of seven spike-related traits and their genetic correlations in wheat using two related RIL populations. Euphytica. 2012;186(1):177192.

44. Xu X, Zhang XB, Shi YF, Wang HM, Feng BH, Li XH, et al. A point mutation in an F-box domaincontaining protein is responsible for brown hull phenotype in rice. Rice Sci. 2016;23(1):1-8.

45. Nelson DC, Lasswell J, Rogg LE, Cohen MA, Bartel B. FKF1, a clock-controlled gene that regulates the transition to flowering in Arabidopsis. Cell. 2000;101:331-340.

46. Samach A, Klenz J, Kohalmi S, Risseeuw E, Haughn G, Crosby W. The UNUSUAL FLORAL ORGANS gene of Arabidopsis thaliana is an F-box protein required for normal patterning and growth in the floral meristem. The Plant journal: for cell and molecular biology. 1999;20:433-445.

47. Cornelia F, Annette K, Stefan H, Petra D. An IQ domain mediates the interaction with calmodulin in a plant cyclic nucleotide-gated channel. Plant Cell Physiol. 2013;54:573-584.

48. Beckmann K, Dzuibany C, Biehler K, Fock H, Hell R, Migge A, et al. Photosynthesis and fluorescence quenching, and the mRNA levels of plastidic glutamine synthetase or of mitochondrial serine hydroxymethyltransferase (SHMT) in the leaves of the wild-type and of the SHMT-deficient stm mutant of Arabidopsis thaliana in relation to the rate of photorespiration. Planta. 1997;202(3):379386.

49. Walker JC. Receptor-like protein kinase genes of Arabidopsis thaliana. The Plant journal: for cell and molecular biology. 2010;3(3):451-456.

50. Rawson HM, Richards RA. Effects of high temperature and photoperiod on floral development in wheat isolines differing in vernalisation and photoperiod genes. Field Crop Res. 1993;32(3):181-192.

51. Shaw LM, Turner AS, Laurence H, Simon G, Laurie DA, Somers DE. Mutant alleles of Photoperiod-1 in wheat (Triticum aestivum L.) that confer a late flowering phenotype in long days. PloS ONE. 2013;8(11):e79459. 
52. Ajmal S, Zakir N, Mujahid M. Estimation of genetic parameters and character association in wheat. J Agric Biol Sci. 2009;1:15-18.

53. Wu XS, Chang XP, Jing RL. Genetic insight into yield-associated traits of wheat grown in multiple rain-fed environments. PloS ONE. 2012;7:e31249.

54. Yao JB, Ren LJ, Zhang PP, Yang XM, Zhou MP. Genetic and correlation analysis of plant height and its components in wheat. J Triticeae Crop. 2011;31:604-610 (in Chinese with English abstract).

55. Kamran A, Iqbal M, Spaner D. Flowering time in wheat (Triticum aestivum L.): a key factor for global adaptability. Euphytica. 2014;197:1-26.

56. Li SS, Jia JZ, Wei XY, Zhang XC, Li LZ, Chen HM, et al. A intervarietal genetic map and QTL analysis for yield traits in wheat. Mol Breed. 2007;20(2):167-178.

57. Quintero A, Molero G, Reynolds MP, Calderini DF. Trade-off between grain weight and grain number in wheat depends on GxE interaction: A case study of an elite CIMMYT panel (CIMCOG). Eur J Agron. 2018;92:17-29.

58. Bancal P. Positive contribution of stem growth to grain number per spike in wheat. Field Crop Res. 2008;105(1):27-39.

59. Miralles DJ, Katz SD, Colloca A, Slafer GA. Floret development in near isogenic wheat lines differing in plant height. Field Crop Res. 1998;59(1):21-30.

60. Li C, Tang HP, Luo W, Zhang XM, Mu Y, Deng M, et al. A novel, validated, and plant height-independent QTL for spike extension length is associated with yield-related traits in wheat. Theor Appl Genet. 2020;133:3381-3393.

61. Bridgemohan P, Bridgemohan RSH. Evaluation of anti-lodging plant growth regulators on the growth and development of rice (Oryza sativa). J Cereals Oilseeds 2014;5:12-16.

62. Ávila-Lovera E, Zerpa AJ, Santiago LS. Stem photosynthesis and hydraulics are coordinated in desert plant species. New Phytol. 2017;216:1119-1129.

\section{Tables}

Table 1 Information of SNP markers in the genetic map 


\begin{tabular}{|llllll|}
\hline Chromosome & Group & $\begin{array}{l}\text { Number of bin } \\
\text { marker }\end{array}$ & $\begin{array}{l}\text { Number of mapped } \\
\text { marker }\end{array}$ & $\begin{array}{l}\text { Length } \\
\text { (cM) }\end{array}$ & $\begin{array}{l}\text { cM per bin } \\
\text { marker }\end{array}$ \\
\hline 1A & 1 & 101 & 586 & 153.29 & 1.52 \\
1B & 1 & 69 & 488 & 149.34 & 2.16 \\
2B & 1 & 66 & 944 & 161.77 & 2.45 \\
3A & 1 & 92 & 423 & 183.69 & 2.00 \\
3B & 1 & 99 & 518 & 160.97 & 1.63 \\
& 1 & 17 & 37 & 49.69 & 2.92 \\
4A & 2 & 27 & 174 & 98.39 & 3.64 \\
4B & 1 & 80 & 282 & 199.90 & 2.50 \\
5A & 1 & 77 & 422 & 83.69 & 1.09 \\
5B & 1 & 92 & 299 & 225.06 & 2.45 \\
6A & 1 & 121 & 675 & 207.52 & 1.72 \\
6B & 1 & 60 & 640 & 167.00 & 2.78 \\
7A & 1 & 58 & 160 & 162.46 & 2.80 \\
7B & 1 & 92 & 395 & 214.20 & 2.33 \\
A genome & 7 & 590 & 499 & 194.81 & 1.97 \\
B genome & 8 & 560 & 3664 & 1282.19 & 2.17 \\
Total & 15 & 1150 & 2878 & 1129.59 & 2.02 \\
\hline
\end{tabular}

Table 2 Phenotypic data and heritability $\left(H^{2}\right)$ of spikelet number per spike (SNS) for the AM population in multiple environments 


\begin{tabular}{|lllllll|}
\hline \multirow{2}{*}{ Environment } & \multicolumn{5}{l}{ Parents } & \multicolumn{4}{ll}{ AL $\times$ LM001 (AM) } & & \\
\cline { 2 - 7 } & AL & LM001 & Min-Max & Mean & SD & $H^{2}$ \\
\hline$E_{1}$ & 25.00 & 24.33 & $20.00-31.67$ & 25.96 & 2.56 & \\
$E_{2}$ & 26.00 & 23.33 & $15.33-33.00$ & 24.41 & 3.22 & \\
$E_{3}$ & 26.33 & 26.00 & $17.00-31.25$ & 24.81 & 2.80 & \\
$E_{4}$ & 26.00 & 25.40 & $18.00-32.00$ & 26.21 & 2.87 & \\
$E_{5}$ & 27.00 & 24.60 & $18.50-31.00$ & 24.99 & 2.42 & \\
$E_{6}$ & 25.80 & 25.40 & $20.00-34.00$ & 26.76 & 2.69 & \\
BLUP & 25.98 & 24.91 & $18.89-30.54$ & 25.53 & 2.09 & 0.82 \\
\hline
\end{tabular}

$B L U P$ phenotype values based on the best linear unbiased prediction, $S D$ standard deviation, $H^{2}$ the broad-sense heritability

Table 3 Correlations of spikelet number per spike (SNS) in the AM population between six environments

\begin{tabular}{|lllllll|}
\hline & $E_{1}$ & $E_{2}$ & $E_{3}$ & $E_{4}$ & $E_{5}$ & $E_{6}$ \\
$E_{1}$ & 1 & $0.500^{\star \star}$ & $0.619^{\star \star}$ & $0.645^{\star \star}$ & $0.521^{\star \star}$ & $0.534^{\star \star}$ \\
$E_{2}$ & 1 & $0.666^{\star \star}$ & $0.631^{\star \star}$ & $0.626^{\star \star}$ & $0.648^{\star \star}$ \\
$E_{3}$ & & 1 & $0.704^{\star \star}$ & $0.672^{\star \star}$ & $0.622^{\star \star}$ \\
$E_{4}$ & & & 1 & $0.761^{\star \star}$ & $0.616^{\star \star}$ \\
$E_{5}$ & & & & 1 & $0.662^{\star \star}$ \\
$E_{6}$ & & & & & 1 \\
\hline
\end{tabular}

$\star \star$ Significance level at $P<0.01$

Table 4 Correlations between spikelet number per spike (SNS) and other agronomic traits in the AM population

\begin{tabular}{|llllllll|}
\hline & PH & AD & PTN & SL & SEL & KNS & TKW \\
\hline SNS & $0.320^{\star *}$ & $0.179^{*}$ & -0.099 & $0.672^{\star *}$ & $0.241^{\star \star}$ & $0.423^{\star *}$ & $0.198^{\star}$ \\
\hline
\end{tabular}

$P H$ plant height, $A D$ anthesis date, $P T N$ productive tiller number, $S L$ spike length, SEL spike extension length, KNS kernel number per spike, TKW thousand kernel weight. *Significance level at $P<0.05$, 
**Significance level at $P<0.01$

Table 5 Quantitative trait loci (QTL) for spikelet number per spike (SNS) identified in multiple environments in the AM population 


\begin{tabular}{|c|c|c|c|c|c|c|c|}
\hline QTL & Env. & $\begin{array}{l}\text { Interval } \\
\text { (cM) }\end{array}$ & Left Marker & Right Marker & LOD & $\begin{array}{l}\text { PVE } \\
(\%)\end{array}$ & Add \\
\hline $\begin{array}{l}\text { QSns.sau-AM- } \\
\text { IA }\end{array}$ & $E_{2}$ & $\begin{array}{l}148.47- \\
153.29\end{array}$ & $\begin{array}{l}A X- \\
110167459\end{array}$ & $\begin{array}{l}A X- \\
110373055\end{array}$ & 6.73 & 14.73 & -1.31 \\
\hline \multirow{2}{*}{$\begin{array}{l}\text { QSns.sau-AM- } \\
3 A\end{array}$} & $\mathrm{E}_{4}$ & 79.51-91.05 & & & 3.03 & 6.91 & 0.69 \\
\hline & $E_{2}$ & 106.81- & 109418113 & 109284498 & 3.26 & 6.11 & -0.85 \\
\hline $\begin{array}{l}\text { QSns.sau-AM- } \\
5 A .1\end{array}$ & $E_{1}$ & 107.24 & $\begin{array}{l}A X- \\
110428951\end{array}$ & AX- & 4.78 & 14.34 & -1.02 \\
\hline \multirow[t]{3}{*}{$\begin{array}{l}\text { QSns.sau-AM- } \\
\text { 5A.2 }\end{array}$} & $E_{3}$ & $\begin{array}{l}116.08- \\
131.93\end{array}$ & $\begin{array}{l}A X- \\
108790581\end{array}$ & $\begin{array}{l}A X- \\
111499991\end{array}$ & $\begin{array}{l}3.17 \\
6.09\end{array}$ & $\begin{array}{l}6.69 \\
10.28\end{array}$ & $\begin{array}{l}-0.74 \\
-0.67\end{array}$ \\
\hline & BLUP & $\begin{array}{l}131.93- \\
135.18\end{array}$ & $A X-$ & $A X-$ & 3.38 & 6.62 & 0.87 \\
\hline & $E_{2}$ & $\begin{array}{l}131.93- \\
135.18\end{array}$ & & & 3.91 & 9.31 & -0.80 \\
\hline $\begin{array}{l}\text { QSns.sau-AM- } \\
6 A\end{array}$ & $\mathrm{E}_{4}$ & $91.51-92.38$ & 111499991 & 111596791 & 3.81 & 12.71 & -0.74 \\
\hline \multirow{2}{*}{$\begin{array}{l}\text { QSns.sau-AM- } \\
2 B .1\end{array}$} & $E_{5}$ & $92.48-94.75$ & $\begin{array}{l}A X- \\
109842268\end{array}$ & $\begin{array}{l}A X- \\
108785002\end{array}$ & 8.19 & 20.27 & -1.21 \\
\hline & $\mathrm{E}_{1}$ & 113.67- & & & 5.00 & 9.64 & -1.04 \\
\hline \multirow{2}{*}{$\begin{array}{l}\text { QSns.sau-AM- } \\
2 B .2\end{array}$} & $E_{2}$ & 114.56 & 109818835 & 108848446 & 10.86 & 27.26 & -1.49 \\
\hline & $E_{3}$ & $\begin{array}{l}127.65- \\
129.44\end{array}$ & $\begin{array}{l}A X- \\
109421413\end{array}$ & $\begin{array}{l}A X- \\
109506426\end{array}$ & 5.71 & 14.16 & -0.98 \\
\hline \multirow{6}{*}{$\begin{array}{l}\text { QSns.sau-AM- } \\
2 B .3\end{array}$} & $\mathrm{E}_{4}$ & $\begin{array}{l}127.65- \\
129.44\end{array}$ & $\begin{array}{l}A X- \\
111626925\end{array}$ & $\begin{array}{l}A X- \\
111588559\end{array}$ & 4.54 & 13.90 & -0.95 \\
\hline & $E_{5}$ & $\begin{array}{l}127.65- \\
129.44\end{array}$ & $\begin{array}{l}A X- \\
111626925\end{array}$ & $\begin{array}{l}A X- \\
111588559\end{array}$ & 13.28 & 26.50 & -1.07 \\
\hline & $\mathrm{E}_{6}$ & 127.65- & & & 6.36 & 18.06 & 1.14 \\
\hline & BLUP & 129.44 & 111626925 & 111588559 & 3.11 & 9.38 & 0.81 \\
\hline & $\mathrm{E}_{4}$ & $\begin{array}{l}127.65- \\
129.44\end{array}$ & $\begin{array}{l}A X- \\
111626925\end{array}$ & $\begin{array}{l}A X- \\
111588559\end{array}$ & 4.13 & 9.57 & 0.85 \\
\hline & $E_{6}$ & $127.65-$ & & $A X-$ & 4.89 & 9.32 & 1.05 \\
\hline \multirow{2}{*}{$\begin{array}{l}\text { QSns.sau-AM- } \\
3 B .1\end{array}$} & $\mathrm{~F}$ & 129.44 & 111626925 & 111588559 & 5.28 & 11.82 & 1.00 \\
\hline & $E_{2}$ & $\begin{array}{l}127.65- \\
129.44\end{array}$ & $\begin{array}{l}A X- \\
111626925\end{array}$ & $\begin{array}{l}A X- \\
111588559\end{array}$ & 2.53 & 8.27 & 0.60 \\
\hline \multirow{6}{*}{$\begin{array}{l}\text { QSns.sau-AM- } \\
3 B .2\end{array}$} & & $22.72-42.47$ & & & 7.81 & 13.74 & 0.79 \\
\hline & $E_{3}$ & $22.72-42.47$ & 111626925 & 111588559 & 4.13 & 7.82 & 0.96 \\
\hline & $E_{5}$ & $48.34-49.69$ & $\begin{array}{l}A X- \\
110399975\end{array}$ & $\begin{array}{l}A X- \\
109050064\end{array}$ & 3.93 & 6.38 & 0.53 \\
\hline & BLUP & $48.34-49.69$ & $A X-$ & & 2.81 & 6.41 & 0.66 \\
\hline & $E_{2}$ & $48.34-49.69$ & 110399975 & 109050064 & 2.67 & 4.23 & 0.43 \\
\hline & BLUP & $48.34-49.69$ & $\begin{array}{l}A X- \\
109393346\end{array}$ & $\begin{array}{l}A X- \\
110548993\end{array}$ & & & \\
\hline
\end{tabular}




\begin{tabular}{|c|c|c|c|c|}
\hline $\begin{array}{l}\text { QSns.sau-AM- } \\
4 B\end{array}$ & $\mathrm{E}_{4}$ & 48.34-49.69 & $\begin{array}{l}A X- \\
109393346\end{array}$ & $\begin{array}{l}A X- \\
110548993\end{array}$ \\
\hline $\begin{array}{l}\text { QSns.sau-AM- } \\
\text { 5B.1 }\end{array}$ & BLUP & $\begin{array}{l}68.66-69.11 \\
131.85- \\
133.16\end{array}$ & $\begin{array}{l}A X- \\
109393346\end{array}$ & $\begin{array}{l}A X- \\
110548993\end{array}$ \\
\hline $\begin{array}{l}\text { QSns.sau-AM- } \\
5 B .2\end{array}$ & & $\begin{array}{l}142.38- \\
143.74\end{array}$ & $\begin{array}{l}A X- \\
109393346\end{array}$ & $\begin{array}{l}A X- \\
110548993\end{array}$ \\
\hline \multirow[t]{5}{*}{$\begin{array}{l}\text { QSns.sau-AM- } \\
6 B\end{array}$} & & $\begin{array}{l}123.88- \\
124.75\end{array}$ & $\begin{array}{l}A X- \\
109393346\end{array}$ & $\begin{array}{l}A X- \\
110548993\end{array}$ \\
\hline & & & $\begin{array}{l}A X- \\
111151524\end{array}$ & $\begin{array}{l}A X- \\
109338618\end{array}$ \\
\hline & & & $\begin{array}{l}A X- \\
110547223\end{array}$ & $\begin{array}{l}A X- \\
108834482\end{array}$ \\
\hline & & & $\begin{array}{l}A X- \\
110911600\end{array}$ & $\begin{array}{l}A X- \\
109870696\end{array}$ \\
\hline & & & $\begin{array}{l}A X- \\
108748222\end{array}$ & $\begin{array}{l}A X- \\
86183685\end{array}$ \\
\hline
\end{tabular}

Env. Environment, BLUP phenotype values based on the best linear unbiased prediction, LOD logarithm of odds, PVE phenotype variance explained, Add additive effect, positive values: alleles from AL were increasing the trait score, negative values: alleles from LM001 were increasing the score

Figures 


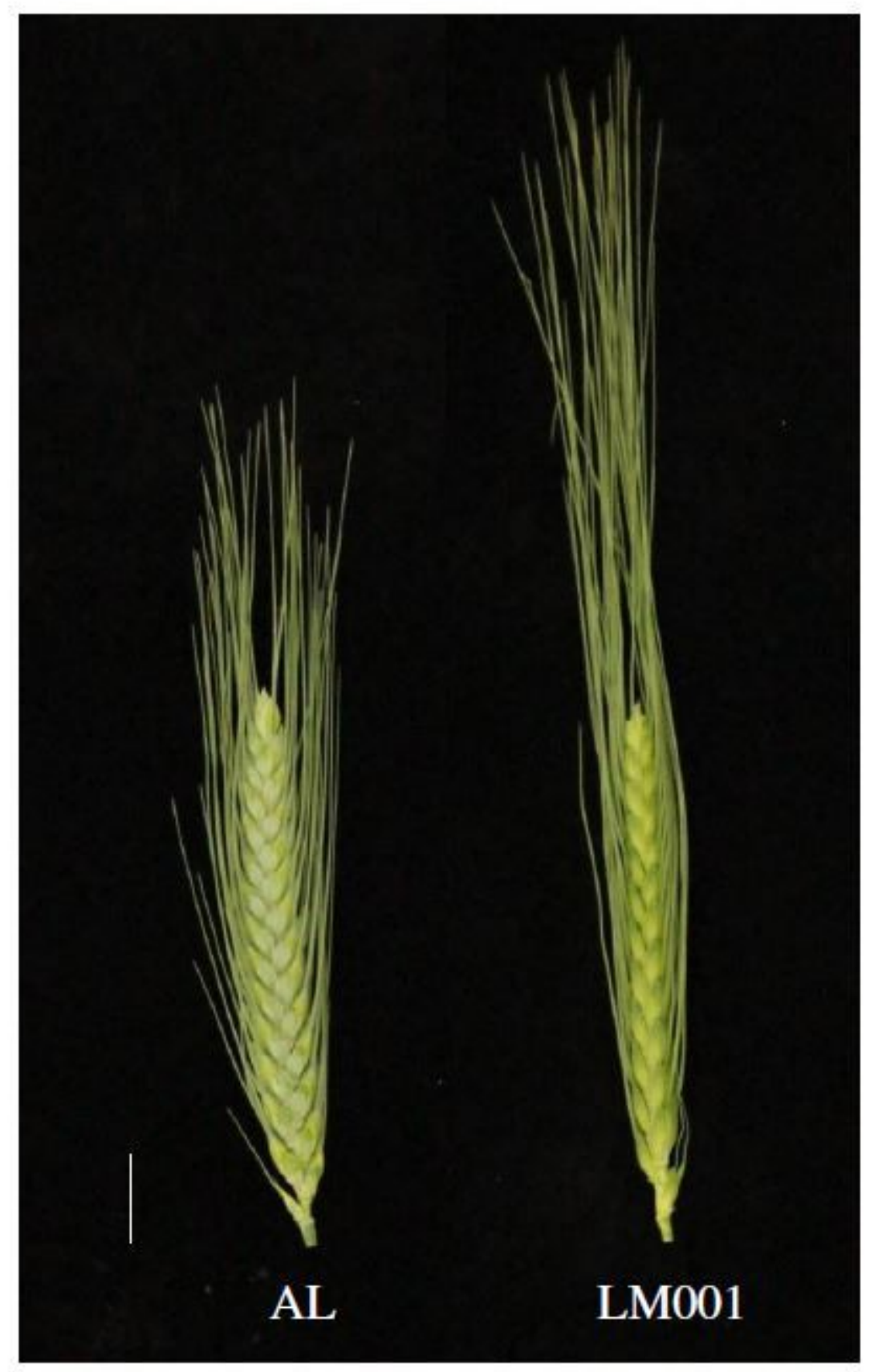

Figure 1

The spikes of AL and LM001 (scale bar $=2 \mathrm{~cm}$ ) 


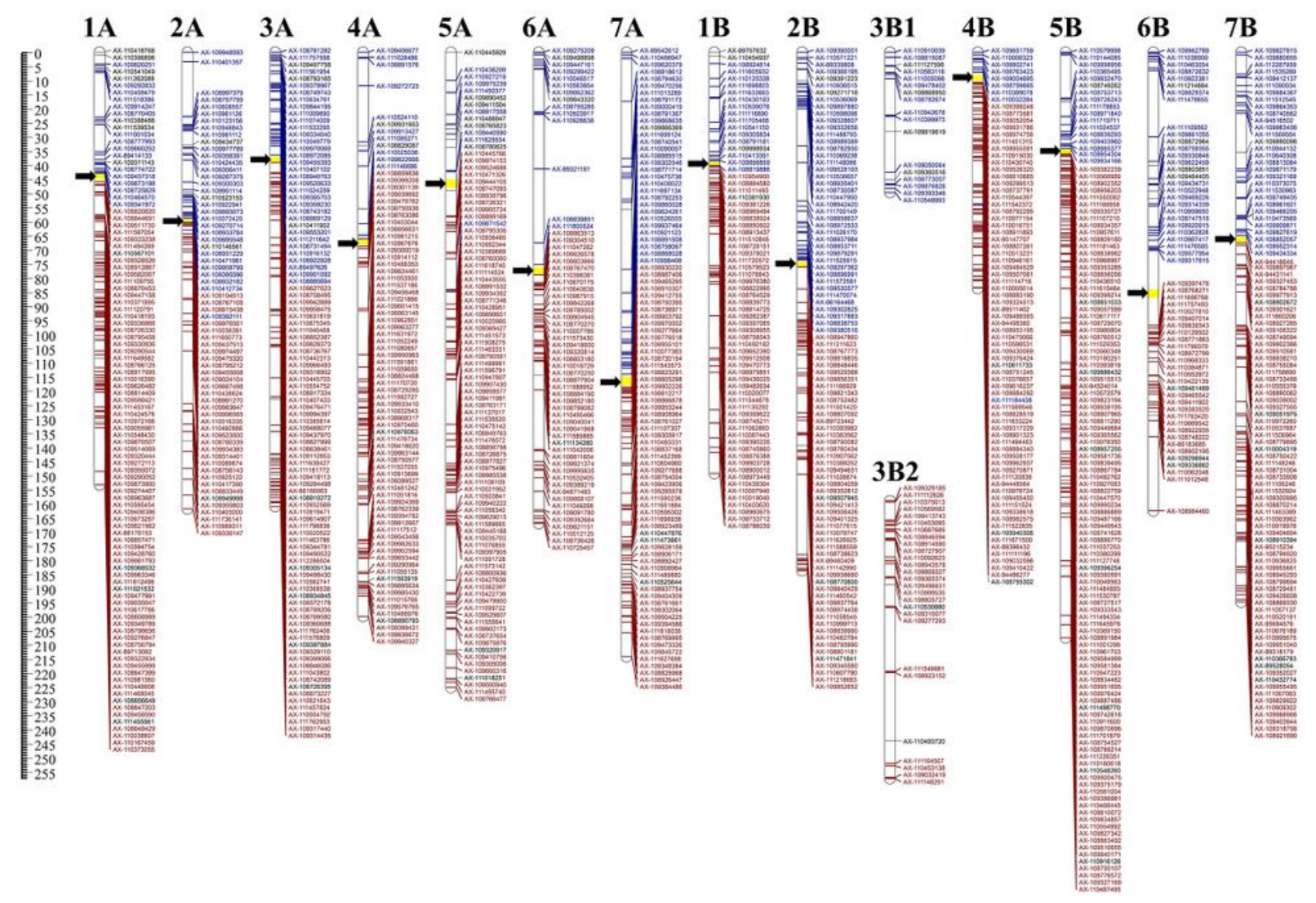

Figure 2

Distribution information of 1150 bin markers on the genetic maps. The positions of centromeres were indicated by yellow areas and black arrows. The short arms (blue) and long arms (red) of chromosomes were in the upper and lower parts, respectively. The markers were black indicated that their physical locations were not on the corresponding chromosomes. The names of bin markers were listed on the right side of the chromosomes 


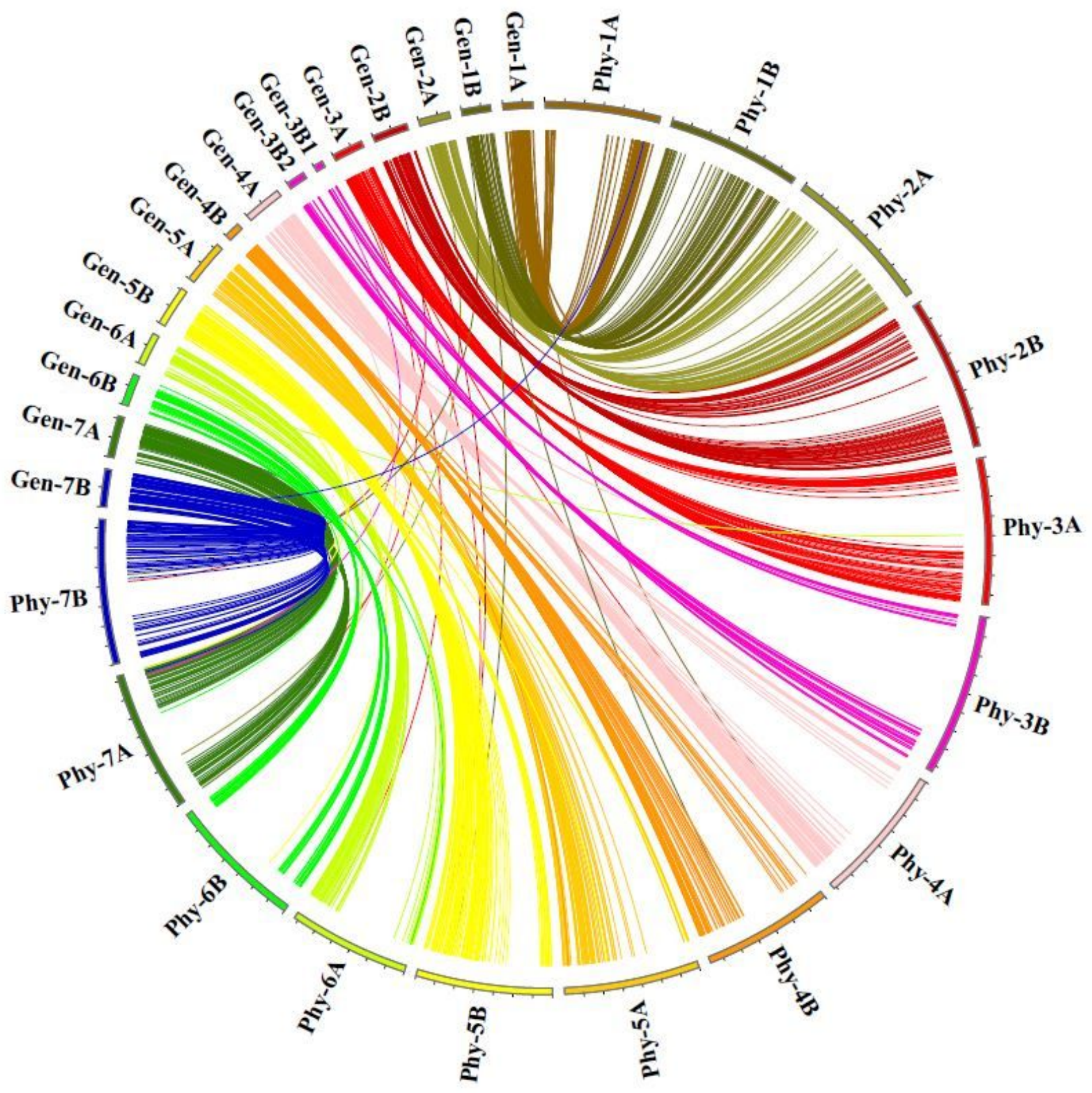

Figure 3

The syntenic relationships between the genetic and physical maps of bin markers (excluding the 49 bin markers of unknown chromosomes). Gen-1A to Gen-7B represented the 15 chromosomal genetic maps used in the current study; Phy-1A to Phy-7B represented the 14 chromosomal physical maps of wild emmer genome 
(a)

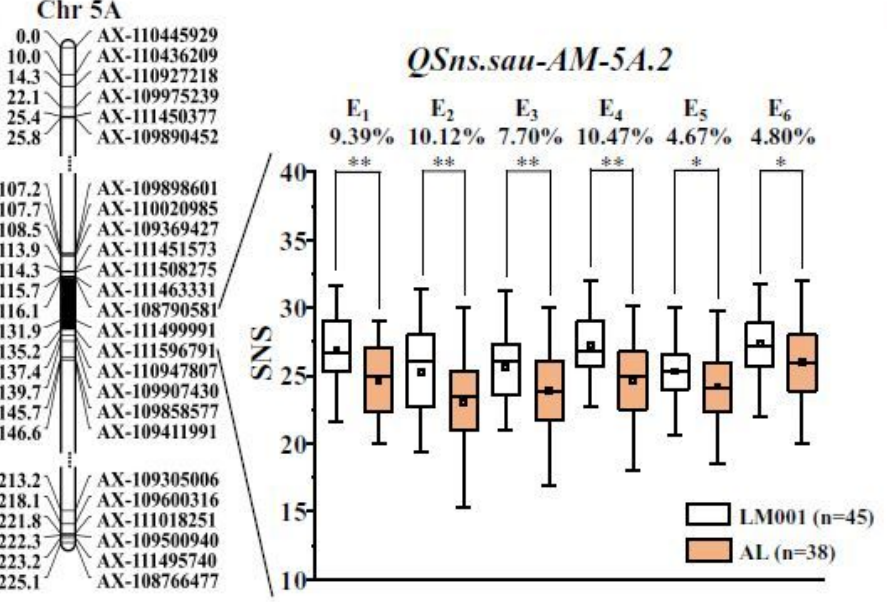

(c)

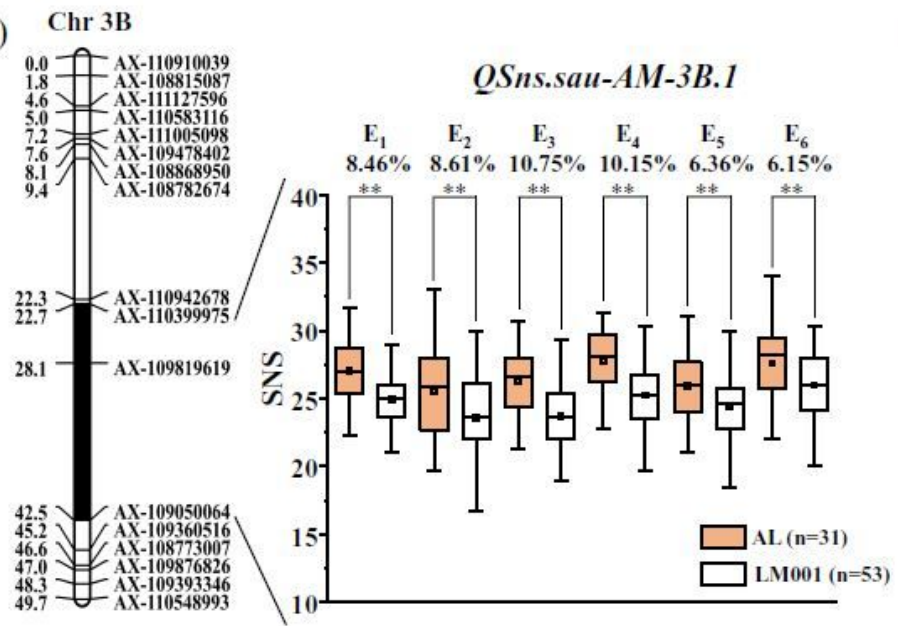

(b)

0.0 Chr 2B $\left.\begin{array}{l}1.9 \\ 2.4\end{array}\right)\left(\begin{array}{c}\mathrm{AX}-110571221 \\ \mathrm{AX}-89339808\end{array}\right.$ 2.4 $\mathrm{A}$ AX-89339808 5.7 ${ }_{\mathrm{AX}-109391223}^{\mathrm{AX}-10966195}$ 6.1 AX-110936515 111.9 $) \mid\left(\begin{array}{l}\text { AX-109507945 } \\ \text { AX-109421413 }\end{array}\right.$ 114.6 AX-109506426 119.8 AX-111077615 120.7 AX-110078747 127.7 AX-111626925 129.4 AX-111588559 130.4 AX-108738623 134.8 AX-89460409 135.2. AX-111142990 135.6] AX-109938690 180.2 / AX-10880118 180.2 2 AX-10880118 181.5 7 晍 AX-10934558 182.8 AX-110607790 183.7 $\begin{array}{r}\text { AX-111218683 } \\ \text { AX-109852652 }\end{array}$

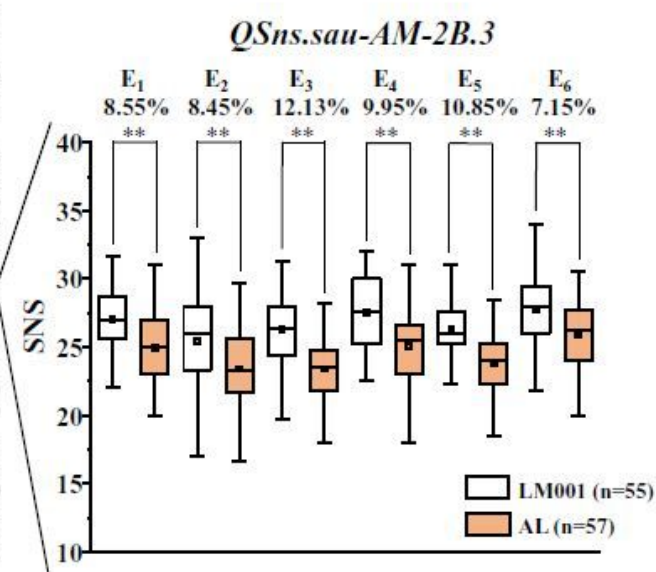

(d) $\mathrm{Chr} 3 \mathrm{~B}$

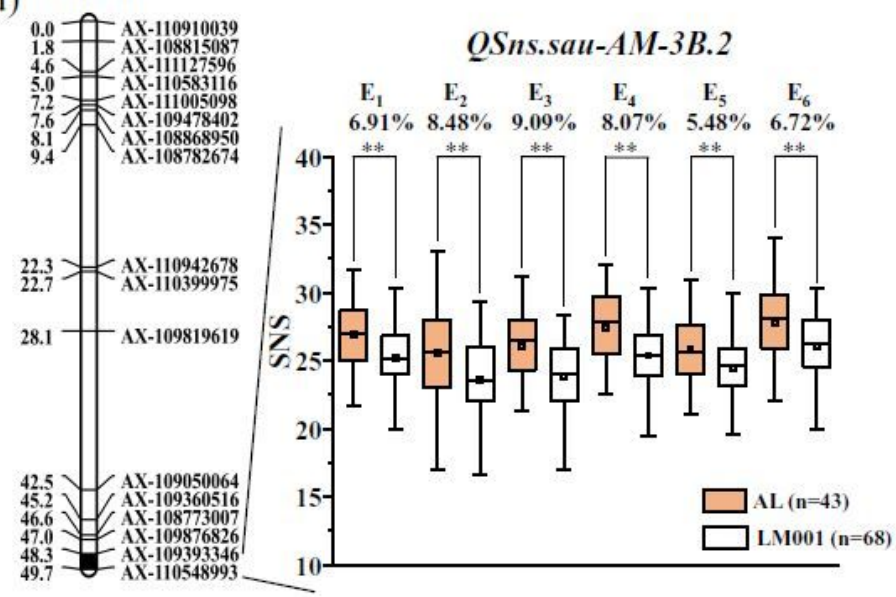

Figure 4

AM RILs were divided into two categories based on the genotype of flanking markers, and the SNS differences caused by the corresponding QTL were represented in the form of boxplots. Genetic maps of QSns.sau-AM-5A.2 (a), QSns.sau-AM-2B.3 (b), QSns.sau-AM-3B.1 (c), QSns.sau-AM-3B.2 (d) and their effects. *Significance level at $P<0.05$, $* *$ Significance level at $P<0.01$. The SNS differences between the two categories were marked below the environment names 


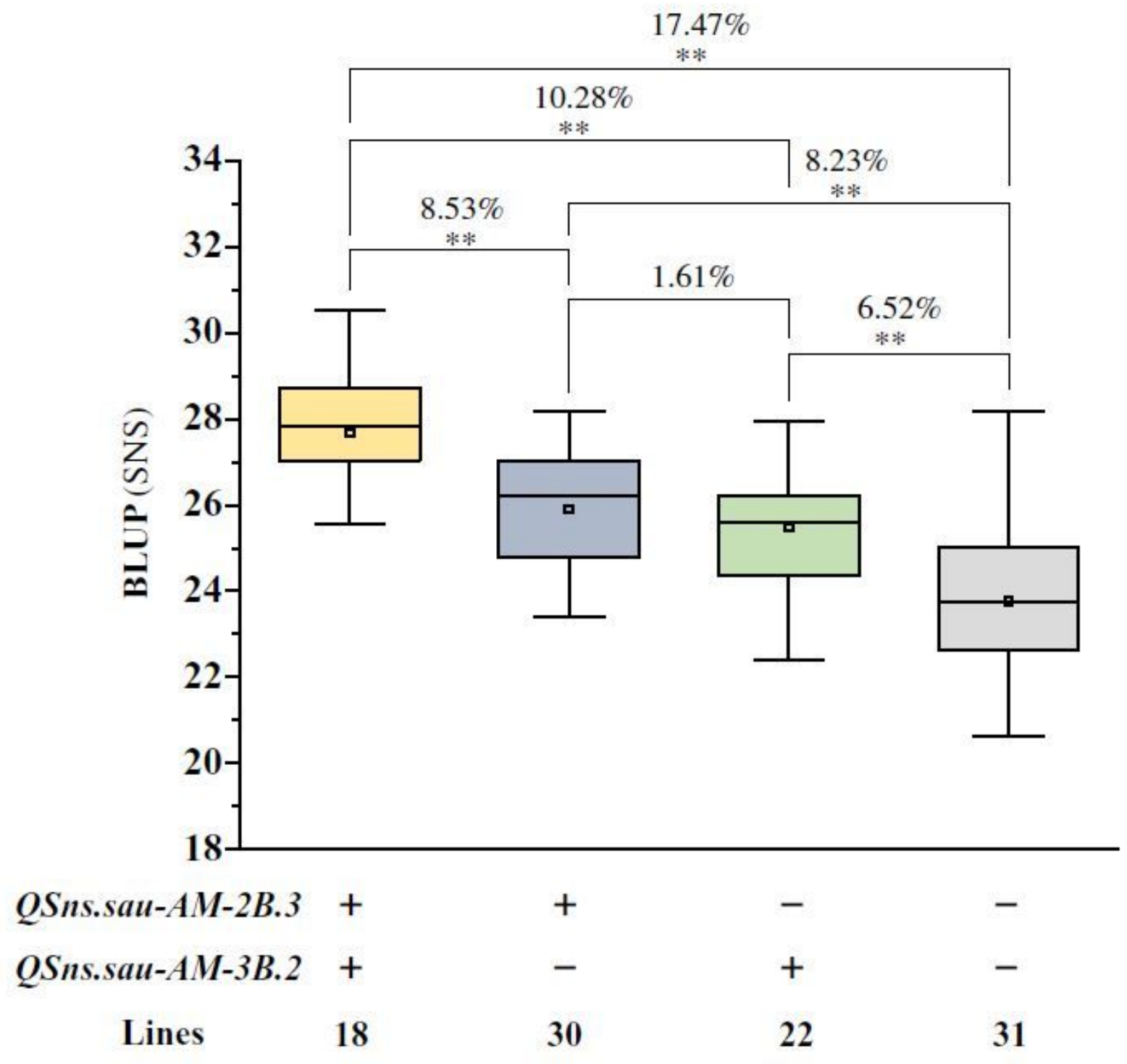

Figure 5

The effects of different combinations of QSns.sau-AM-2B.3 and QSns.sau-AM-3B.2 on increasing SNS in the AM population. ' + ' and '-' represented lines with and without the positive allele of the corresponding QTL based on the genotype of flanking markers, respectively. *Significance level at $P<0.05$, $\star \star$ Significance level at $\mathrm{P}<0.01$ 

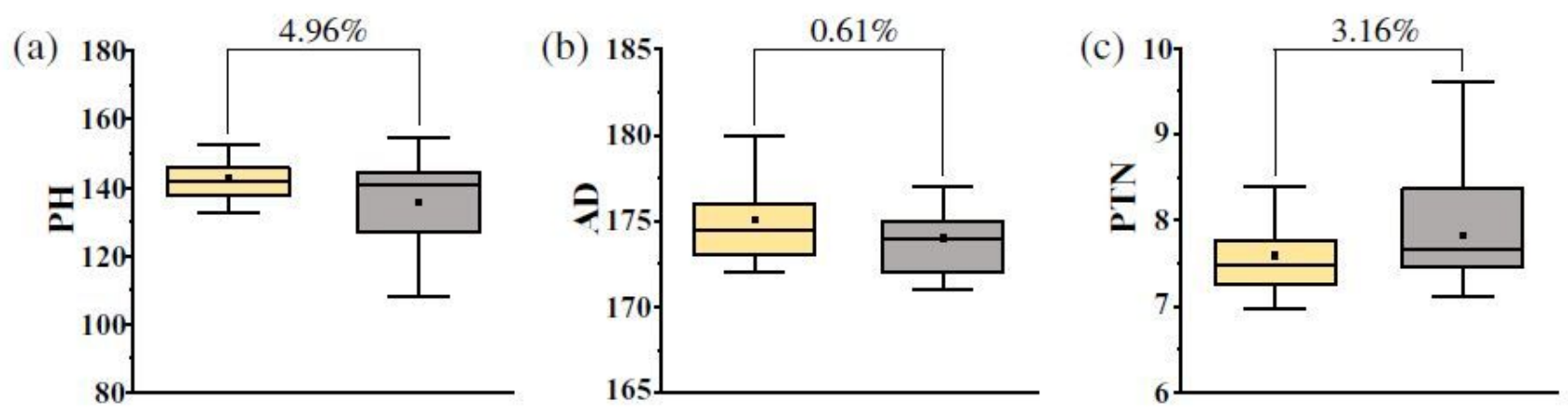

$10.92 \%$
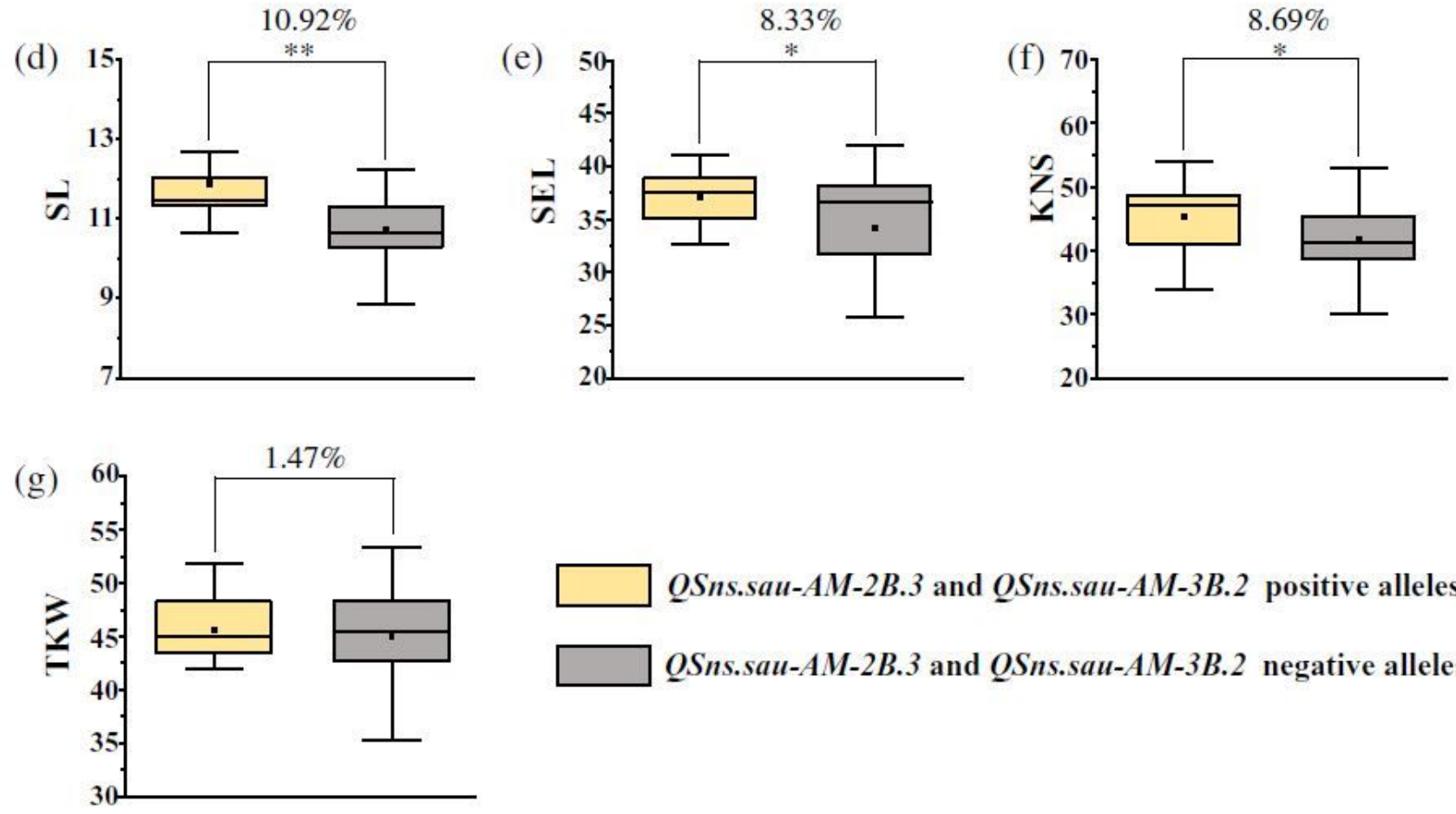

QSns.sau-AM-2B.3 and QSns.sau-AM-3B.2 positive alleles $(\mathrm{n}=18)$

QSns.sau-AM-2B.3 and QSns.sau-AM-3B.2 negative alleles $(\mathrm{n}=31)$

\section{Figure 6}

Student's t-test against the two categories of lines from the AM RIL population possessing the positive or negative alleles of both QSns.sau-AM-2B.3 and QSns.sau-AM-3B.2 for (a) plant height (PH); (b) anthesis date (AD); (c) productive tiller number (PTN); (d) spike length (SL); (e) spike extension length (SEL); (f) kernel number per spike (KNS); (g) thousand kernel weight (TKW). *Significance level at $P<0.05$, $\star \star$ Significance level at $P<0.01$. Differences between the two categories of lines were marked above the significance levels 
(a)

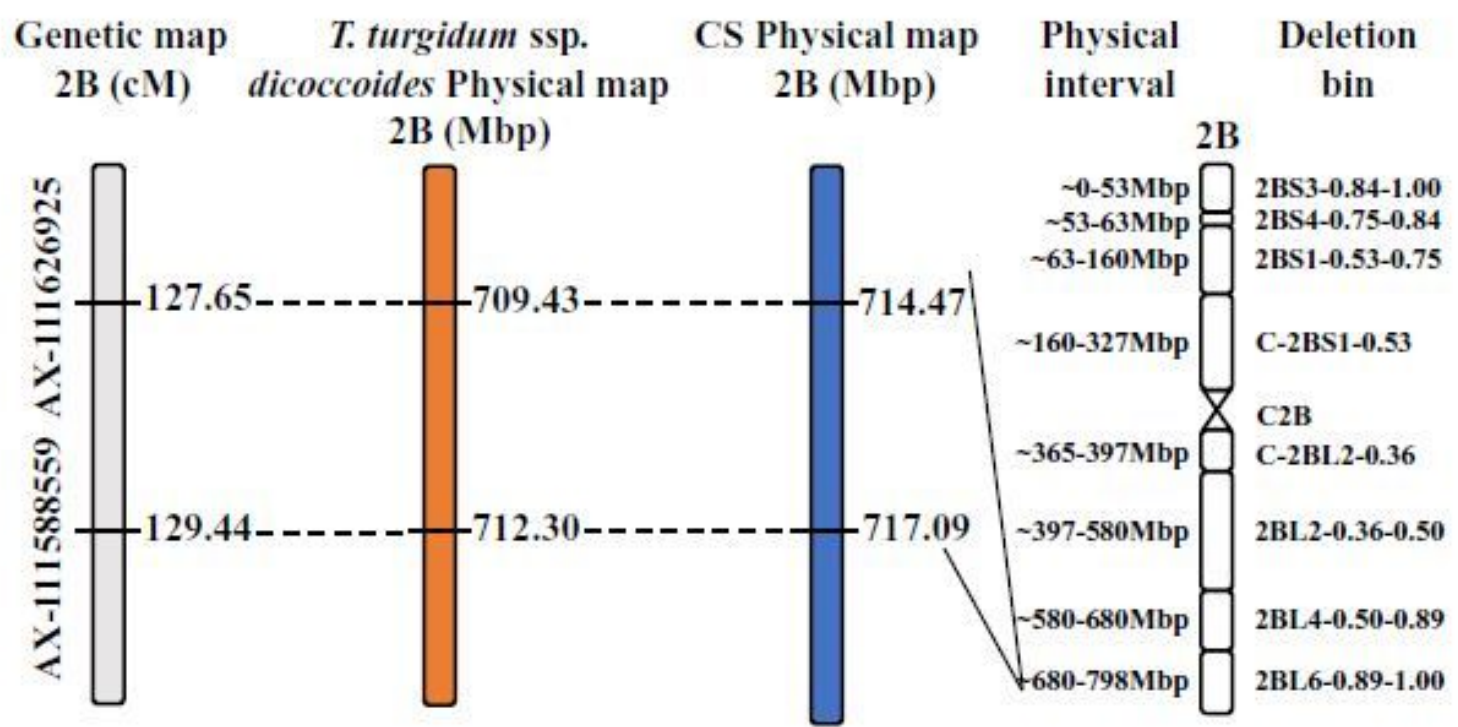

$\begin{array}{ccccc}\text { (b) Genetic map } & \text { T. turgidum ssp. } & \text { CS Physical map } & \text { Physical } & \text { Deletion } \\ \text { 3B1 (cM) } & \text { dicoccoides Physical map } & \text { 3B (Mbp) } & \text { interval } & \text { bin }\end{array}$

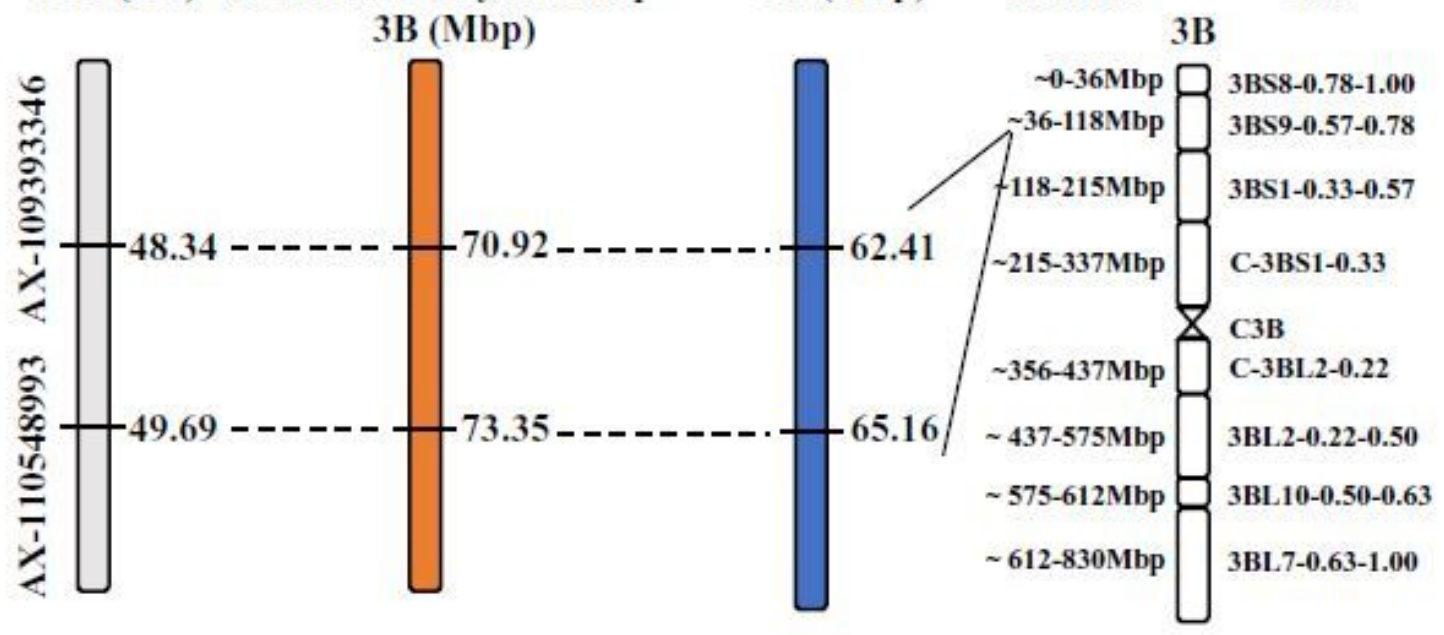

Figure 7

The physical intervals of QSns.sau-AM-2B.3 (a) and QSns.sau-AM-3B.2 (b)

\section{Supplementary Files}

This is a list of supplementary files associated with this preprint. Click to download.

- Additionalfile1.xlsx

- Additionalfile2.xlsx

- Additionalfile3.xlsx 
- Additionalfile4.pdf

- Additionalfile5.pdf

- Additionalfile6.xlsx

- Additionalfile7.xlsx

- Additionalfile8.xlsx

- Additionalfile9.xlsx

- Supplementaryinformationdescription.docx 